\title{
Necessidade de incentivo ao desenvolvimento da horta escolar nas instituições da rede pública
}

\author{
Need to encourage the development of school vegetable-garden in \\ public schools institutions
}

\author{
Selson Garutti \\ Licenciado em Filosofia - USC (Bauru) e História - UEM (Maringá); \\ Especialista em Pesquisa Educacional - UEM; \\ Mestre em Ciências da Religião - PUC-SP; \\ Doutorando em Educação - Universidade Estadual de Ponta Grossa; \\ Professor de Filosofia - Estado do Paraná. \\ selsongarutti@hotmail.com \\ Priscila Peralta \\ Licenciada em Ciências Biológicas - Centro Universitário de Maringá. \\ priscilaperalta@hotmail.com
}

\begin{abstract}
Resumo
Hoje, educação ambiental é um tema que apresenta real importância para todos. Implantá-la nas escolas tem-se mostrado uma tarefa exaustiva. Existem grandes dificuldades nas ações de sensibilização e de formação quando da implantação de atividades e projetos, principalmente na manutenção e continuidade dos já existentes. Uma das formas para ressaltar o tema da educação ambiental nas escolas é a que se dá por meio do desenvolvimento da horta escolar. As hortaliças são alimentos essenciais para a dieta humana pelo fato de apresentarem alto valor nutritivo em fibras, vitaminas e sais minerais. Estima-se que o consumo de frutas e hortaliças, no Brasil, corresponda a menos da metade das recomendações nutricionais, sendo ainda mais deficiente entre as famílias de baixa renda. A horta escolar pode servir como fonte de alimentação e de atividades didáticas, oferecendo grandes vantagens às comunidades envolvidas como a obtenção de alimentos de qualidade a baixo custo e o envolvimento em programas de alimentação e saúde desenvolvidos pelas escolas. No presente trabalho, temos a finalidade de incentivar as escolas da rede pública de Maringá no desenvolvimento da horta escolar e na percepção de seus benefícios.
\end{abstract}

Palavras-chave: Educação ambiental. Horta escolar. Hortaliças.

\begin{abstract}
In the current days, the Environmental Education is a theme that presents a real importance for all. To implement the Environmental Education in schools has been an exhaustive task. There are great difficulties in raising awareness and training when the implementation of activities and projects, mainly in the maintenance and continuity of the existing ones. One of the ways to emphasize the theme of environmental education inside the schools it is through the development of the school vegetablegarden. The vegetables are essential foods for the human diet because of its high nutritional value in fibers, vitamins and mineral salts. It is considered that the consumption of fruits and vegetables in Brazil corresponds to less half of the nutritional recommendations, being still more deficient among of low-income families. The school vegetable garden can serve as a source and didactic activities, offering great advantages to the involved communities, as the obtaining of quality foods at a low cost and also the involvement in feeding programs and health developed by the schools. In the present work we have the purpose to motivate the public schools of Maringá city for the development of the school vegetable-garden and the benefits obtained through them.
\end{abstract}

Key words: Environmental education. School vegetable-garden. Vegetables. 


\section{Introdução}

Nos dias atuais, educação ambiental é um tema que apresenta real importância para todos. É papel da escola conscientizar os alunos a respeito dos problemas gerados pela interferência do homem no meio ambiente e fazer despertar a preocupação em preservá-lo e com ele viver em harmonia. A escola pode incentivar a educação ambiental por meio do desenvolvimento da horta escolar.

Uma melhor qualidade de vida é obtida a partir do momento em que se tem preocupação com os alimentos que são ingeridos, lembrando que o consumo de uma alimentação não balanceada pode levar à subnutrição ou ao sobrepeso. Um dos alimentos do qual se conhecem os benefícios, por apresentarem nutrientes fundamentais para o bom funcionamento do nosso organismo, são as hortaliças, que apesar disso ainda são consumidos em pequena quantidade.

Além dos benefícios obtidos a partir da implantação da horta - a exemplo das hortaliças frescas que poderão incrementar a merenda escolar com custo mínimo -, os alunos poderão utilizá-la como laboratório vivo para o aprendizado de diversas disciplinas, aprendendo as técnicas de seu cultivo e, o mais importante, conhecendo a importância de seu consumo para o bom desenvolvimento do nosso organismo.

Neste trabalho, temos por finalidade incentivar as escolas da rede pública de Maringá ao desenvolvimento da horta escolar, apresentando os benefícios obtidos.

\section{Educação ambiental por meio da horta escolar}

Nas últimas décadas, intensificaram-se as preocupações inerentes à temática ambiental e, concomitantemente, as iniciativas dos variados setores da sociedade para o desenvolvimento de atividades e projetos de educação das comunidades, procurando sensibilizá-las para as questões ambientais, mobilizá-las para a modificação de atitudes nocivas e incentivá-las à apropriação de posturas benéficas ao equilíbrio ambiental. (RUY, 2004)

Implantar a Educação Ambiental nas escolas tem-se mostrado uma tarefa exaustiva. Existem grandes dificuldades nas atividades de sensibilização e formação, na estruturação de atividades e projetos e, principalmente, na manutenção e continuidade dos já existentes. Fatores como o tamanho da escola, o 
número de alunos e de professores, a predisposição dos docentes em passar por um processo de treinamento, a vontade da diretoria de realmente implantar um projeto ambiental que altere as rotinas da escola etc., além de fatores resultantes da integração dos envolvidos, podem servir como obstáculos à implantação desse tipo de atitude. Dado que a educação ambiental não se dá por atividades pontuais, mas por toda uma mudança de paradigmas que exige uma contínua reflexão e apropriação dos valores que remetem a ela, as dificuldades enfrentadas assumem características ainda mais contundentes. (ANDRADE apud RUY, 2004)

Uma das formas de ressaltar o tema educação ambiental dentro das escolas é o uso da horta escolar. Segundo Carvalho (2001), quando fala sobre a capacidade de a educação promover valores ambientais, é importante destacar que o processo educativo não se dá apenas pela aquisição de informações, mas, sobretudo, pela aprendizagem ativa, entendida como construção de novos sentidos e nexos para a vida. Trata-se de um processo que envolve transformações do sujeito que aprende e incide sobre sua identidade e suas posturas diante do mundo.

O ser humano aprendeu, desde a pré-história, a praticar a agricultura a fim de assegurar o seu sustento. Com o tempo, essa técnica sofreu muitas modificações, passando a utilizar intensivamente agrotóxicos e fertilizantes, irrigação, novas variedades genéticas e maquinarias, o que acabou, de certa forma, agravando a degradação ambiental e a produção de riscos aos seres humanos. A aplicação indiscriminada de agrotóxicos acarretou inúmeros problemas, tanto para saúde dos aplicadores e dos consumidores quanto para o meio ambiente (DI GIOVANNI; ZANETTI, 2006).

É indispensável deixar de lado a agricultura convencional e caminhar na direção de uma agricultura mais autossustentável e menos agressiva à natureza. A agricultura ecológica apresenta-se como um espaço em construção que pode trazer amplos benefícios para quem produz, para quem consome e para o conjunto do meio ambiente.

\section{Os diferentes grupos de hortaliças e seu valor nutricional das hortaliças}

Segundo Filgueira (1987), olericultura é o termo técnico-científico para o estudo da cultura das plantas oleráceas, ou hortaliças, popularmente conhecidas 
como "verduras" e "legumes", termos incorretos e pouco esclarecedores. Dentro do amplo e complexo universo da olericultura, com sua multiplicidade de espécies e variedades, é útil distinguir, desde já, três grupos bem diferentes de hortaliças que podem contribuir para a dieta diária das pessoas.

\section{Tabela 1: Três diferentes grupos de hortaliças}

\begin{tabular}{c|c|c}
\hline Tipos de hortaliças & Parte aproveitável & Exemplos \\
\hline Hortaliças herbáceas & $\begin{array}{c}\text { As partes aproveitáveis para } \\
\text { o consumo humano são } \\
\text { aéreas, desenvolvem-se } \\
\text { acima do solo, são tenras e } \\
\text { suculentas, consistindo em } \\
\text { folhas, flores ou talos }\end{array}$ & $\begin{array}{c}\text { Alface, repolho, espinafre, } \\
\text { couve-flor, aspargo, entre } \\
\text { outros exemplos }\end{array}$ \\
\hline Hortaliças tuberosas & $\begin{array}{c}\text { A parte comestível } \\
\text { desenvolve-se dentro do solo, } \\
\text { sendo caracteristicamente } \\
\text { rica em carboidratos (amido } \\
\text { e açúcares), consistindo em } \\
\text { raízes e caules tuberosos }\end{array}$ & $\begin{array}{c}\text { Cenoura, mandioquinha- } \\
\text { salsa, batatinha, batata doce } \\
\text { e cará são bons exemplos }\end{array}$ \\
\hline Hortaliças frutos & $\begin{array}{c}\text { Produzem frutos comestíveis } \\
\text { que são consumidos quando } \\
\text { ainda verdes ou após a } \\
\text { completa maturação, no } \\
\text { todo ou em parte }\end{array}$ & $\begin{array}{c}\text { Tomate, quiabo, feijão-de- } \\
\text { vagem são alguns exemplos }\end{array}$ \\
\hline
\end{tabular}

Fonte: COSTA (2005).

As hortaliças são alimentos essenciais para a dieta humana pelo fato de apresentarem alto valor nutritivo como fibras, vitaminas e sais minerais. Tais nutrientes se tornam indispensáveis para o bom funcionamento do organismo, desempenhando importante papel como antioxidante, e são capazes de prevenir e até controlar doenças como diabetes, hipertensão, doenças cardiovasculares e mesmo o câncer (SALGADO, 2006). Evidências epidemiológicas têm demonstrado que existe uma forte correlação inversa entre o consumo regular de frutas e hortaliças e a prevalência de algumas doenças degenerativas (MELO et al., 2006). Substâncias antioxidantes como as vitaminas C e E e os carotenóides, presentes nas frutas e hortaliças, reduzem o risco de câncer inibindo danos oxidativos no DNA, já que a fase de iniciação desse tipo de doença está associada a dano irreversível 
no material genético da célula, muitas vezes devido ao ataque de radicais livres (SILVA; NAVES, 2001). Sobre os nutrientes encontrados nas hortaliças, tem-se:

- Carboidratos, que oferecem energia sob a forma de açúcares;

- Proteínas, moléculas essenciais para construir e manter músculos, cabelos e tecidos do corpo. Importantes, principalmente, no crescimento durante a infância;

- Vitaminas, que estão envolvidas no bom funcionamento dos aparelhos circulatório, respiratório e digestório, além de atuar, juntamente com outros nutrientes, para formar enzimas e controlar a queima de açúcares e proteínas dentro das células;

- Minerais, que ajudam na formação da estrutura do corpo, por exemplo, dos ossos. (IRALA; FERNANDEZ, 2001)

A ausência de alguns minerais na alimentação pode resultar em doenças como anemia (deficiência de ferro no organismo), osteoporose (deficiência de cálcio) e bócio (deficiência de iodo). (op.cit.)

\subsection{Alimentação saudável para uma vida saudável}

Segundo Pinheiro e Gentil (2005), uma alimentação saudável entendida como direito humano compreende um padrão alimentar adequado às necessidades biológicas e sociais dos indivíduos de acordo com as fases da vida. Tem por característica três princípios:

1. Variedade - ingestão de diferentes tipos de alimentos pertencentes aos diversos grupos;

2. Moderação - não exagero nas quantidades de alimentos ingeridas;

3. Equilíbrio - consumo de alimentos variados, respeitando a quantidade de porções recomendadas para cada grupo de alimentos.

Entre os problemas da nutrição do brasileiro, assumem grande evidência os chamados "alimentos protetores", que incluem as hortaliças. Sua importância deriva dos elevados teores de sais minerais e vitaminas, que contêm substâncias 
Tabela 2: Exemplos de nutrientes e benefícios de determinadas hortaliças

\begin{tabular}{|c|c|c|}
\hline Hortaliça & Valor nutricional & Combate \\
\hline Tomate & $\begin{array}{c}\text { Vitamina } \mathrm{A}, \mathrm{C}, \mathrm{E}, \text { ferro e } \\
\text { potássio }\end{array}$ & $\begin{array}{c}\text { Maior resistência dos vasos } \\
\text { sanguíneos e combate a infecções }\end{array}$ \\
\hline Cenoura & $\begin{array}{l}\text { Vitamina A, vitaminas do } \\
\text { complexo B, cálcio, fósforo }\end{array}$ & $\begin{array}{l}\text { Regula o aparelho digestivo, } \\
\text { purifica a bile e fortalece a pele }\end{array}$ \\
\hline Cebolinha & Cálcio, ferro, niacina & $\begin{array}{l}\text { Estimula o apetite, ajuda na } \\
\text { formação de ossos e dentes }\end{array}$ \\
\hline Abobrinha & $\begin{array}{l}\text { Cálcio, ferro, vitaminas do } \\
\text { complexo B e fósforo }\end{array}$ & $\begin{array}{l}\text { Contra a fadiga mental, ajuda na } \\
\text { formação de glóbulos vermelhos }\end{array}$ \\
\hline Salsa & Ferro e vitamina A & Diurético, revitalizante \\
\hline Alface & $\begin{array}{c}\text { Ferro, cálcio, niacina, vitamina } \\
\text { C }\end{array}$ & $\begin{array}{l}\text { Combate insônia, ajuda na } \\
\text { cicatrização dos tecidos }\end{array}$ \\
\hline Almeirão & $\begin{array}{c}\text { Vitaminas do complexo B e } \\
\text { vitamina A }\end{array}$ & Protege a pele \\
\hline Beterraba & $\begin{array}{l}\text { Vitamina C, açúcar, vitamina } \\
\text { do complexo B e vitamina A }\end{array}$ & $\begin{array}{c}\text { Laxante, combate anemia e } \\
\text { descongestionante das vias } \\
\text { urinárias }\end{array}$ \\
\hline Couve & $\begin{array}{l}\text { Ferro, vitamina A, cálcio, } \\
\text { fósforo }\end{array}$ & $\begin{array}{c}\text { Tônico, cicatrizante, estimulante } \\
\text { do fígado }\end{array}$ \\
\hline Repolho & Vitamina A e C & $\begin{array}{c}\text { Combate infecções, depurativo do } \\
\text { sangue, estimula a produção de } \\
\text { hormônios }\end{array}$ \\
\hline Rúcula & Iodo, vitamina A e C & $\begin{array}{c}\text { Combate a fadiga e depura o } \\
\text { sangue }\end{array}$ \\
\hline Manjerona & Sais minerais & $\begin{array}{c}\text { Estimula a eliminação de muco } \\
\text { nas vias respiratórias }\end{array}$ \\
\hline Erva Cidreira & Sais minerais & $\begin{array}{c}\text { Tonico nervoso, combate cólicas } \\
\text { intestinais }\end{array}$ \\
\hline Hortelã & Sais minerais & Analgésico, vermífugo \\
\hline Brócolos & Sais minerais & $\begin{array}{l}\text { Flatulência, cólicas abdominais, } \\
\text { diarreia }\end{array}$ \\
\hline Espinafre & $\begin{array}{l}\text { Vitamina A, tianina, potássio, } \\
\text { ferro }\end{array}$ & $\begin{array}{c}\text { Combate a desnutrição, manchas } \\
\text { na pele e diabetes }\end{array}$ \\
\hline Berinjela & $\begin{array}{l}\text { Sais minerais, sódio, } \\
\text { vitamina A }\end{array}$ & Antioxidante, baixa colesterol \\
\hline
\end{tabular}

Fonte: COSTA (2005). 
reconhecidamente imprescindíveis à saúde humana. Na dieta do brasileiro, as hortaliças não são alimentos básicos nem são ingeridas em grandes quantidades como acontece com o arroz, o feijão e a carne. O papel delas é de valioso complemento vitamínico-mineral, não se esperando que contribuam com teores elevados de carboidratos, proteínas e gorduras. Entretanto, sua participação diária na dieta é uma garantia de saúde, sendo muito mais desejável do que substituí-las por cápsulas coloridas adquiridas a preços exorbitantes nas farmácias (FILGUEIRA, 1987). Estima-se que o consumo de frutas e hortaliças no Brasil corresponda a menos da metade das recomendações nutricionais, sendo ainda mais deficiente entre as famílias de baixa renda. (JAIME et al., 2007)

Um fator determinante para a má nutrição é o aumento da oferta de alimentos do tipo "refeições rápidas", o que vem se tornando um fator de extrema importância nos padrões alimentares das pessoas cuja rotina de vida é cada vez mais agitada. Isso fica evidente na oferta alimentar disponibilizada por muitos pais, que tendem a optar pelos lanches industrializados na alimentação de seus filhos em razão da correria do dia a dia e da falta de tempo (DARTORA et al., 2006). Cabe ressaltar que o organismo humano não é capaz de armazenar vitaminas e sais minerais necessários à sua nutrição (FILGUEIRA, 1987); devido a este fato, necessita consumir, diariamente, entre outros alimentos, diferentes variedades de hortaliças cruas e cozidas. (AMORIM, 1987)

Para fortalecer o vínculo positivo entre educação e saúde, devemos promover um ambiente saudável, melhorando a educação e o potencial de aprendizagem ao mesmo tempo em que promovemos a saúde. Do conjunto de temas que podem compor esse ambiente promotor, a alimentação tem papel de destaque, pois permite que a criança traga suas experiências particulares e exercite uma experiência concreta. Uma alimentação que não cumpre as "Leis da Nutrição" pode resultar, por exemplo, em aumento de peso e deficiência de vitaminas e minerais. (IRALA; FERNANDEZ, 2001)

Segundo Schiessel (2002), no Brasil o problema da obesidade tem se agravado nas últimas décadas. O percentual de pessoas obesas vem aumentando enquanto o de pessoas subnutridas diminui. A obesidade apresenta-se como uma doença da modernidade, resultado do desenvolvimento tecnológico que proporcionou maior demanda de alimentos, aliado a mudanças na composição das dietas que aumentou o consumo de gorduras, açúcares, alimentos refinados e redução de ingestão de carboidratos complexos e fibras. Ela constitui fator de risco para a 
hipertensão arterial, hipercolesterolemia, diabetes mellitus, doenças cardiovasculares e algumas formas de câncer (MARTINS apud SCHIESSEL, 2002). A subnutrição - consumo insuficiente de nutrientes essenciais para a saúde - mata cerca de uma criança a cada seis segundos, pois debilita o organismo e facilita a contração de várias doenças como hemorragia gastrointestinal, dor de cabeça, visão dupla, raquitismo, osteoporose, escorbuto, edemas, aumento da glândula tireóide, doenças coronárias e outras. (CABRAL, 2007)

Um dos fatores que levam ao não consumo desses alimentos está no fato de serem produtos perecíveis, que passam pelas mãos de alguns intermediários até chegar aos pontos de venda com baixa qualidade. Cabe lembrar que esses alimentos necessitam de alguns cuidados quando transportados, para que não haja contaminação. 0 transporte das hortaliças sob condições ideais de temperatura e umidade relativa prolonga o tempo de vida de prateleira e mantém suas características intrínsecas de qualidade física e sensorial, tornando-os mais atraentes. Além disso, a manutenção de baixa temperatura durante o transporte pode também inibir o crescimento de patógenos. (MORAES, 2006)

Há vários fatores que influenciam o comportamento alimentar: fatores externos (unidade familiar e suas características, atitudes de pais e amigos, valores sociais e culturais, mídia, alimentos rápidos, conhecimentos de nutrição e manias alimentares) e fatores internos (necessidades e características psicológicas, imagem corporal, valores e experiências pessoais, autoestima, preferências alimentares, saúde e desenvolvimento psicológico) (MELLO et al., 2004). A formação e a adoção de hábitos saudáveis devem ser estimuladas em crianças, pois é durante os primeiros anos de vida que elas definirão seus hábitos alimentares e de cuidados físicos. Dessa forma, a promoção da saúde assume um papel de educação para a saúde. (IRALA; FERNANDEZ, 2001)

\section{A horta na escola}

A escola do futuro é uma escola onde as crianças gostarão de estudar, onde terão boa perspectiva de futuro, onde se promove o interesse e a curiosidade, onde serão ajudadas a se tornarem responsáveis e independentes no que diz respeito a sua aprendizagem. O uso da horta escolar como recurso educacional pode ser um meio para alcançar esses objetivos. Sendo o processo educativo o maior 
ativo transformador de uma sociedade, as propostas de educação infantil devem ser um instrumento de reflexão crítica, contribuindo para um entendimento das novas relações políticas, econômicas e sociais que desenvolva a capacidade de análise das crianças sobre a realidade ao seu redor (LIRA; OLIVEIRA, apud XAVIER, 2007). Ensino e aprendizagem podem acontecer na horta escolar e isso pode ser um complemento ao que é ensinado nas salas de aula e vice-versa. Por meio das atividades desenvolvidas para formar uma horta também nos tornamos conscientes de que fazemos parte da teia da vida, de que estamos inseridos num ecossistema e numa paisagem que apresenta fauna e flora peculiares, em um sistema social que possui uma cultura própria. (XAVIER, 2007)

Pela primeira vez uma pesquisa foi feita com o intuito de avaliar a merenda escolar. AAssociação Brasileira de Nutrição (Asbran) foi escolhida para a realização da pesquisa por meio de seleção pública lançada pela Financiadora de Estudos e Projetos (Finep), em 2005. De acordo com a presidente da Associação, Andréa Polo Galante (VASCONCELOS, 2007, p. 8), a alimentação escolar tem que fornecer ao estudante pelo menos 15\% dos nutrientes diários necessários: "É fundamental que, na hora em que o aluno está na escola, tenha uma alimentação adequada para ajudar no aprendizado, rendimento e desenvolvimento". A horta escolar pode servir como fonte de alimentação e de atividades didáticas, oferecendo grandes vantagens às comunidades envolvidas como a obtenção de alimentos de qualidade a baixo custo e envolvimento em programas de alimentação e saúde desenvolvidos pelas escolas. (NOGUEIRA, 2005)

Para iniciar uma horta na escola, não há necessidade de contarmos com grandes espaços. Pequenos corredores e canteiros vazios, beiras de cercas ou cercados ao longo do prédio, jardins abandonados ou mal aproveitados podem transformar-se em locais de cultivo dos mais diferentes tipos de hortaliças, pois elas são plantas de pequeno porte (RASCHE, 1992). A falta de espaço para construção de canteiros não impede que a escola cultive hortaliças. Recipientes como latas, bacias, caixas e vasos ou qualquer outro material alternativo que acondicione certo volume de solo capaz de abrigar as raízes das plantas podem ser utilizados para o cultivo. (CARDOSO et al., 2005)

Caso seja possível, o preparo da horta deve ser feito sob a orientação de um agrônomo ou técnico agrícola. Porém, se a escola já tem algum pai, professor ou funcionário com o conhecimento prático do cultivo de hortaliças, essa pessoa poderá ajudar. A escolha das hortaliças deve optar pela diversidade, garantindo 


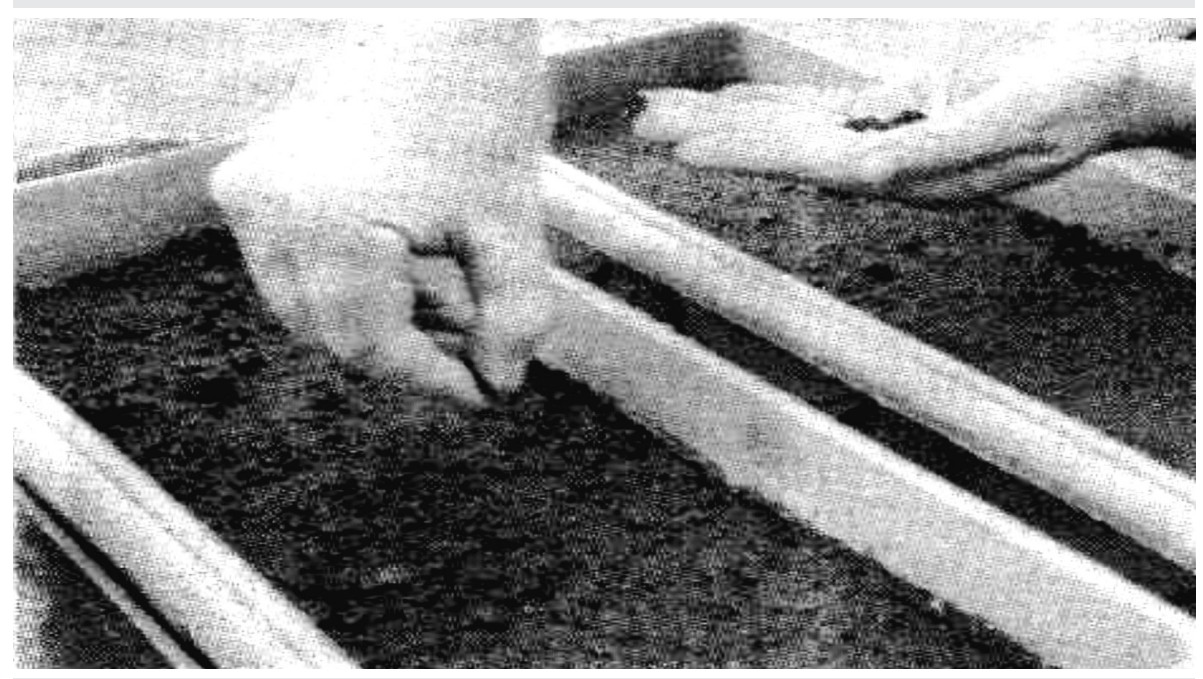

Figura 1: Imagem do cultivo de hortaliças em vasos

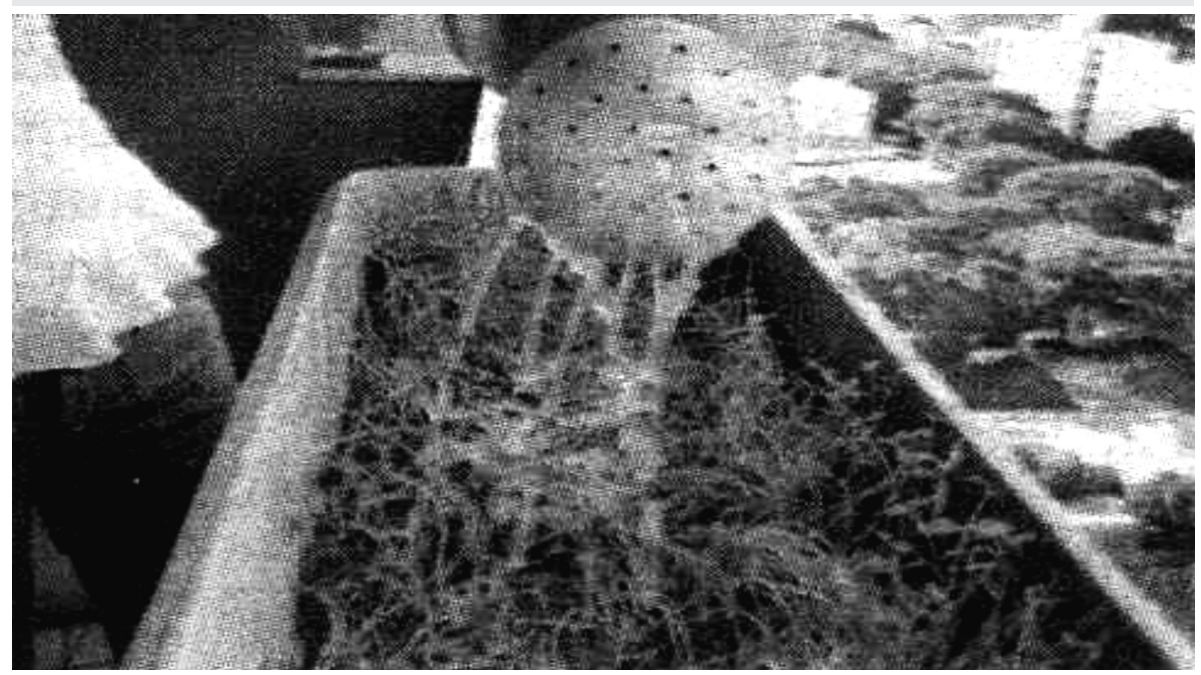

Figura 2: Desenvolvimento das hortaliças nos vasos

uma grande variedade de cores, formas e, assim, nutrientes. O trabalho conjunto da escola com a família tem a finalidade de estabelecer um conceito de alimentação saudável, incentivando o desenvolvimento da horta nas escolas para que os alunos tenham contato direto com a produção de alimentos sadios e higiênicos. A tarefa do cultivo de hortaliças pode proporcionar momentos agradáveis 
de descontração, participação coletiva dos alunos e confiança nas suas próprias capacidades. Segundo Sheila Ceccon (2010), hortas escolares são instrumentos que, dependendo do encaminhamento dado pelo educador, podem abordar diferentes conteúdos curriculares de forma significativa e contextualizada e promover vivências que resgatam valores.

\section{Considerações finais}

Com base na bibliografia levantada, podem ser observados os problemas ocasionados pelo consumo de uma alimentação não balanceada e a importância vital da ingestão de determinados alimentos denominados "protetores", como as hortaliças.

Fica nítida a importância e os benefícios que o desenvolvimento da horta escolar pode proporcionar tanto para as escolas - os alimentos nela produzidos poderão incrementar a merenda escolar - quanto para os alunos, já que leva a conhecer os benefícios das hortaliças na alimentação, base para motivar a implantação de seu cultivo em quintais domésticos.

Ainda mais importante é a possibilidade de uma horta poder servir como campo de estudos em que os alunos aprenderão sobre os problemas ocasionados pela interferência do homem no meio ambiente e sobre a importância e as medidas a serem tomadas para preservá-lo.

\section{Referências}

AMORIM, Urivaldo de Almeida. Programa de Hortas Domésticas e Comunitárias. Ministério da Agricultura, Pecuária e Abastecimento - MAPA. Junho de 1987. Disponível em: www.200.198.51.220/scriptcase/file/docacervo/Programas\%20de\%20Hortas\%20 Domesticas\%20e\%20Comunitarias.pdf. Acesso em: 23 mar. 2010.

CABRAL, Gabriela. Subnutrição. Equipe Brasil Escola, 2007. Disponível em: www.forum. brasilescola.com/index.php?showtopic=31577. Acesso em: 3/ ago. 2010.

CARDOSO, João Marcos Martins et al. Horta na lata - Promovendo saúde e qualidade de vida. Anais... Encontro de Extensão da UFMG, 8, Belo Horizonte, out. 2005. Disponível em: www.ufmg.br/proex/arquivos/8Encontro/Meio_6.pdf. Acesso em: 18 mar. 2010. 
CARVALHO, Isabel Cristina de Moura. Qual educação ambiental? Elementos para um debate sobre educação ambiental e extensão rural. Agroecol. e Desenv. Rur. Sustent., Porto Alegre, v. 2, n. 2, abr./jun. 2001. Disponível em: www.emater.tche.br/docs/agroeco/revista/ ano2_n2/index.htm - 4k. Acesso em: 11 jun. 2010.

CECCON, Sheila. Horta escolar: um importante instrumento de educação ambiental. Disponível em: www.atibaia.com.br/interativo/colunista01.asp?recnum=17. Acesso: 7 mar. 2010 .

COSTA, Cândido Alves da. et al. Horta na lata - Promovendo saúde e qualidade de vida. SIEXBRASIL: 17769. Temática principal: meio ambiente área temática secundária: Saúde. Anais. . . Encontro de Extensão da UFMG, 8, Belo Horizonte -3 a 8 de Outubro de 2005. Disponível em: www.ufmg.br/proex/arquivos/8encontro/meio_6.pdf. Acesso em: 5 jun. 2010.

DARTORA, Nessana; VALDUGA, Alice Tereza; VENQUIARUTO, Luciana. Alimentos e saúde: uma questão de educação 2006. Disponível em: www.reitoria.uri.br/ vivencias/ Numero_004/artigos/vencedores/area_saude/area_saude.htm. Acesso em: 10 mar. 2010.

DI GIOVANNI, Patrícia Carla; ZANETTI Camila Brunhari. Educação ambiental e construção de horta orgânica na escola: um alerta sobre o cultivo e o consumo de produtos com agrotóxicos. Revista Hispeci \& Lema. São Paulo, v. 9, 2006. Disponível em: http://www. fafibe.br/down/revista/revista9.pdf. Acesso em: 23 mar. 2010.

FILGUEIRA, Fernando Antônio Reis. ABC da olericultura: guia da pequena horta. São Paulo: Agronômica Ceres, 1987.

IRALA, Clarissa Hoffman; FERNANDEZ, Patrícia Martins. Manual para escolas - Horta. Brasília, 2001. Disponível em: www.univag.com.br/ /Enfermagem/Alimentação\%20e\%20 Nutrição/Manual\%20para\%20escolas,\%20horta/horta.pdf. Acesso em: 3 mar. 2010.

JAIME, Patrícia Constante et al. Educação nutricional e consumo de frutas e hortaliças: ensaio comunitário controlado. Rev. Saúde Pública, fev. 2007, v. 41, n. 1, p.154-157. Disponível em: www.scielo.br/pdf/rsp/v41n1/5823.pdf. Acesso em: 16 mar. 2010.

MELO, Elza D. de; LUFT, Vivian C.; MEYER, Flavia. Obesidade infantil: como podemos ser eficazes? Jornal da Pediatria. Porto Alegre, v. 80, n. 3, 2004. Disponível em: www.scielo.br/ pdf/jped/v80n3/v80n3a04.pdf. Acesso em: 10 ago. 2010.

MELO, Enayde de Almeida et al. Capacidade antioxidante de hortaliças usualmente consumidas. Ciênc. Tecnol. Aliment. v. 26, n. 3. Campinas, jul./set. 2006. Disponível em: www.scielo.br/pdf/cta/v26n3/31768.pdf. Acesso em: 6 mar. 2010.

MORAES, Ingrid Vieira Machado de. Dossiê Técnico - Conservação de hortaliças. Rede de Tecnologia do Rio de Janeiro, nov. 2006. Disponível em: www.sbrt.ibict.br/upload/dossies/ sbrt-dossie31.pdf?PHPSESSID $=$ f7c213686dca5c48f89c6d7706a0f966. Acesso em: 6 mar. 2010.

NOGUEIRA, Wedson Carlos Lima. Horta na escola - Uma alternativa de melhoria na alimentação e qualidade de vida. Anais. . . Encontro de extensão da UFMG, 8. Belo Horizonte, out. 2005. Disponível em: www.ufmg.br/proex/arquivos/8Encontro/Meio_5.pdf. Acesso em: 11 jul. 2010. 
PINHEIRO, Anelise Rizzolo de Oliveira; GENTIL, Patrícia Chaves. A iniciativa de incentivo ao consumo de frutas, verduras e legumes (f.1 \&v): uma estratégia para abordagem intersetorial no contexto da Segurança Alimentar e Nutricional (CONSEA - Brasil). Ministério da Saúde - Secretaria de Atenção à Saúde - Departamento de Atenção Básica - CoordenaçãoGeral da Política de Alimentação e Nutrição. Brasília, DF, 2005. Disponível em: WWW. dtr2004.saude.gov.br/nutricao/documentos/iicflv_br_consea.pdf. Acesso em: 13 jun. 2010. RASCHE, Laerte, Em qualquer lugar a horta é viável. Revista do Professor, Porto Alegre, p. 20-23, out. /dez. 1992,

RUY, Rosimari A. Viveiro. A educação ambiental na escola. Revista Eletrônica de Ciências. n. 26, maio 2004. Disponível em: www.cdcc.sc.usp.br/ciencia/artigos/art_26/ eduambiental.html-20k. Acesso em: 17 jul. 2010.

SALGADO, Jocelem Mastrode. Frutas, hortaliças e grãos integrais da prevenção de doenças. 2006. Disponível em: www.sbaf.org.br/sbaf/_alimentos/200506_Importancia_ frutas.htm. Acesso: 5 mar. 2010.

SILVA, Cyntia Rosa de Melo; NAVES, Maria Margareth Veloso. Suplementação de vitaminas na prevenção de câncer. Rev. Nutr. v.14, n. 2. Campinas, maio/ago. 2001. Disponível em: www.scielo.br/scielo.php?pid=S1415-52732001000200007\&script=sci_arttext $-78 \mathrm{k}$. Acesso em: 4 abr. 2010.

VASCONCELOS, Luciana. Governo Federal vai avaliar merendas nas escolas. Jornal Hoje. Maringá, 12 ago. 2007, 1-B Geral, p.08.

XAVIER, Bruno Toribio de Lima et al. Fortalecimento da educação escolar indígena diferenciada através da comunicação rural. Anais. . Enapet, 11, Florianópolis-SC, [2007?]. Disponível em: www.enapet.ufsc.br/inscricoes.php-22k. Acesso em: 22 jul. 2010.

recebido em 12 ago. 2011 / aprovado em 26 jun. 2012

\section{Para referenciar este texto:}

GARUTTI, S.; PERALTA, P. Necessidade de incentivo ao desenvolvimento da horta escolar nas instituições da rede pública. Dialogia, São Paulo, n. 15, p. 93-105, 2012. 
